\title{
Therapeutic potential of a phospholipase D1 inhibitory peptide fused with a cell- penetrating peptide as a novel anti- asthmatic drug in a Der $f$ 2-induced airway inflammation model
}

\author{
Yun Young Lee', So Young Lee ${ }^{1}$, Shin-Young Park², Hye-Jin Choi ${ }^{2}$, Eung-Gook Kim³ and Joong-Soo Han (iD ${ }^{1,2}$
}

\begin{abstract}
Asthma is a chronic lung disease that causes airflow obstruction due to airway inflammation. However, its therapeutics remain inadequate. We previously reported that phospholipase D1 (PLD1) is a key enzyme involved in the production of pro-inflammatory cytokines in airway inflammation induced by the house dust mite allergen Dermatophagoides farinae 2 (Der $f$ 2). We also revealed that PLD1 is specifically inactivated by AP180 (assembly protein, $180 \mathrm{kDa}$ ) and identified the PLD1-specific binding motif (TVTSP) of AP180. Therefore, the aims of this study were to develop a novel anti-asthmatic agent that could suppress airway inflammation by inhibiting PLD1 and examine its acute and chronic toxicity. We designed TAT-TVTSP, a PLD1-inhibitory peptide fused with a cell-penetrating peptide (CPP) delivery system. TAT-TVTSP was efficiently delivered to bronchial epithelial cells and significantly reduced Der $f$ 2-induced PLD activation and Interleukin 13 (IL-13) production. Intranasally administered TAT-TVTSP was also efficiently transferred to airway tissues and ameliorated airway inflammation in a Der $f$ 2-induced allergic asthma mouse model. Moreover, we investigated the safety of TAT-TVTSP as a therapeutic agent through single- and repeated-dose toxicity studies in a mouse model. Taken together, these results indicated that a PLD1-inhibitory peptide fused with a cell-penetrating peptide may be useful for treating allergic inflammatory asthma induced by house dust mites (HDMs).
\end{abstract}

\section{Introduction}

Allergic asthma is a heterogeneous inflammatory lung disease that affects $\sim 334$ million people worldwide ${ }^{1,2}$. The disease is caused by individual genetic factors and is aggravated by environmental insults such as viral

Correspondence: Eung-Gook Kim (egkim@chungbuk.ac.kr) or Joong-Soo Han (jshan@hanyang.ac.kr)

'Department of Biomedical Sciences, Graduate School of Biomedical Science and Engineering, Hanyang University, Seoul 04763, Republic of Korea

${ }^{2}$ Biomedical Research Institute and Department of Biochemistry and Molecular Biology, College of Medicine, Hanyang University, Seoul 04763, Republic of Korea

Full list of author information is available at the end of the article

These authors contributed equally: Yun Young Lee, So Young Lee. infection, irritants, and allergens in dust, animal fur, and pollen ${ }^{1}$. In most cases, patients with asthma are prescribed inhaled corticosteroids with or without longlasting $\beta$ agonists, theophyllines, or leukotriene-receptor antagonists, according to their symptoms ${ }^{3}$. However, these anti-asthmatic therapies are limited to symptomatic treatment and may incur severe side effects. Furthermore, despite receiving multiple therapies, $\sim 40 \%$ of patients with asthma remain symptomatic, and up to $5 \%$ have difficultto-control asthma ${ }^{3,4}$. In this context, many researchers have focused on improving disease control by studying methods to reduce the administration of corticosteroids

\section{(c) The Author(s) 2018}

Open Access This article is licensed under a Creative Commons Attribution-NonCommercial-NoDerivatives 4.0 International License, which permits any non-commercial cc. ${ }_{\text {BY }}$ No No use, sharing, distribution and reproduction in any medium or format, as long as you give appropriate credit to the original author(s) and the source, and provide a link to the Creative Commons license. You do not have permission under this license to share adapted material derived from this article or parts of it. The images or other third party material in this article are included in the article's Creative Commons license, unless indicated otherwise in a credit line to the material. If material is not included in the article's Creative Commons license and your intended use is not permitted by statutory regulation or exceeds the permitted use, you will need to obtain permission directly from the copyright holder. To view a copy of this license, visit http://creativecommons.org/licenses/by-nc-nd/4.0/. 
to patients with severe allergic asthma. Nevertheless, the number of patients with asthma has not fallen much.

House dust mites (HDMs) are the most prevalent triggers of asthma, and $\sim 85 \%$ of asthmatics are allergic to $\mathrm{HDMs}^{5}$. In particular, Dermatophagoides pteronyssinus $(\operatorname{Der} p)$ and $D$. farinae $(\operatorname{Der} f)$ stimulate the production of Th2 pro-inflammatory cytokines, including Interleukin 4 (IL-4) and Interleukin 13 (IL-13) $)^{5,6}$. We have reported that phospholipase D1 (PLD1) is a key enzyme in the production of IL-13 in response to Der $f 2$ and have suggested that it is a potential therapeutic target in allergic disorders ${ }^{7,8}$. PLD1 is a membrane-associated enzyme that catalyzes the hydrolysis of phosphatidylcholine to yield the lipid second messenger phosphatidic acid and free polar head group choline ${ }^{9}$. However, targeting of PLD1 can incur systemic adverse effects because it is a ubiquitous enzyme involved in membrane trafficking ${ }^{10}$, cytoskeletal rearrangement ${ }^{11}$, differentiation ${ }^{12,13}$, survival $^{14,15}$, and autophagy ${ }^{16}$. Although small-molecule PLD1 inhibitors showed significant therapeutic effects in can$\operatorname{cer}^{17,18}$, autoimmunity ${ }^{19}$, and kidney disease ${ }^{20}$, their use is limited because of side effects, selectivity, and toxicity. We previously reported that PLD1 is specifically inactivated by binding to AP180 (assembly protein, $180 \mathrm{kDa}$ ), an important factor in clathrin-mediated endocytosis of synaptic vesicles ${ }^{21,22}$. Moreover, we identified the PLD1specific binding motif of AP180 and demonstrated that the pentapeptide (TVTSP) in this motif was effective as an anticancer adjuvant ${ }^{23}$. Thereafter, based on these reports, we registered two domestic patents ${ }^{24,25}$. However, it is not known whether this peptide has any therapeutic potency in allergic diseases, including asthma.

Efficient delivery of therapeutic biomolecules to target tissues is a challenging problem because they poorly penetrate the cellular membrane. Cell-penetrating peptides (CPPs), small cationic peptides derived from proteins that can cross phospholipid bilayers, offer one possible solution ${ }^{26}$. CPPs, as a helpful tool for the intracellular delivery of various molecules, such as peptides, proteins, siRNAs, and therapeutic agents, have been studied in various fields ${ }^{27}$. In particular, TAT (trans-activator of transcription) is internalized via clathrin-mediated endocytosis and micropinocytosis and is assumed to be biologically inert ${ }^{28}$. It has been used in preclinical models to study pain ${ }^{29}$, ischemia ${ }^{30}$, cancer $^{31}$, and inflammation ${ }^{32}$, and there have been over 20 phase I and phase II clinical trials involving more than 2000 patients treated with CPPfused therapeutics ${ }^{33}$. These results imply that CPPs can be used as an efficient drug delivery system.

Here, we aimed to develop a novel agent that suppressed airway inflammation by targeting PLD1 and to assess its in vivo toxicity. We designed TAT-TVTSP, a PLD1-specific inhibitory peptide fused with TAT, as the delivery vehicle. TAT-TVTSP effectively penetrated bronchial epithelial cells and airway tissues and significantly reduced $\operatorname{Der} f$ 2-induced PLD activation and airway inflammation in vitro as well as in vivo. Furthermore, TAT-TVTSP was found to be relatively safe in single- and repeated-dose toxicity studies of a mouse model. These findings indicate that therapy using a PLD1inhibitory peptide fused with a CPP delivery system can be an efficient and promising strategy to prevent allergic asthma induced by HDMs.

\section{Materials and methods \\ Cell culture}

BEAS-2B, a human bronchial epithelial cell, was purchased from the American Type Culture Collection (ATCC; Manassas, VA, USA). BEAS-2B cells were cultured in DMEM/F-12 with $10 \%(\mathrm{v} / \mathrm{v})$ heat-inactivated FBS, $100 \mathrm{U} / \mathrm{ml}$ penicillin, and $100 \mu \mathrm{g} / \mathrm{ml}$ streptomycin (Wisent INC, St.-Bruno, QC, Canada) at $37^{\circ} \mathrm{C}$ in a humidified 5\% $\mathrm{CO}_{2}$-controlled incubator.

\section{Materials}

The house dust mite allergen $\operatorname{Der} f 2$ was provided by the Arthropods of Medical Importance Resource Bank, Yonsei University, College of Medicine (Seoul, Korea), as described previously ${ }^{8}$. Peptides were synthesized by CosmoGenetech (Seoul, Korea) and were validated by HPLC and mass spectrometry (data not shown). PLD inhibitors (FIPI and VU0155069) were supplied by Tocris (Oxford, UK).

\section{Determination of PLD activity}

PLD activity was determined in $\left[{ }^{3} \mathrm{H}\right]$-palmitic acidlabeled cells by measuring the amount of $\left[{ }^{3} \mathrm{H}\right]$-phosphatidylbutanol (PBt) produced by PLD-catalyzed transphosphatidylation in the presence of 1-butanol, as described previously $^{34}$. BEAS-2B cells were labeled with $2 \mu \mathrm{Ci} / \mathrm{ml}$ $\left[{ }^{3} \mathrm{H}\right]$-palmitic acid (DuPont-New England Nuclear, Boston, MA, USA) in serum-free medium for $18 \mathrm{~h}$. They were then pretreated with $0.3 \%(\mathrm{v} / \mathrm{v})$ 1-butanol for $15 \mathrm{~min}$ before stimulation with $\operatorname{Der} f$ 2. Cells were pre-incubated with TAT, TAT-TVTSP, FIPI, or VU0155069 for $2 \mathrm{~h}$ after labeling with $\left[{ }^{3} \mathrm{H}\right]$-palmitic acid. After treatment with Der $f 2$ for $30 \mathrm{~min}$, the cells were washed with ice-cold PBS and suspended in ice-cold methanol. Lipids were extracted, and PBt was separated by thin layer chromatography using an ethylacetate/isooctane/acetic acid/water $(26: 4: 6: 20, \mathrm{v} / \mathrm{v})$ solvent system. Authentic PBt bands $\left(R_{\mathrm{f}}=\right.$ $0.76)$ were identified with $0.002 \%(\mathrm{w} / \mathrm{v})$ primulin dissolved in $80 \%(\mathrm{v} / \mathrm{v})$ acetone, scraped, and counted in a liquid scintillation counter (PerkinElmer, Norwalk, CT, USA).

\section{Real-time PCR and reverse transcription (RT)-PCR}

Total cellular RNA was isolated using RNAiso Plus (Takara Bio, Ohtsu, Japan). Next, $2 \mu \mathrm{g}$ of isolated total 
RNA was mixed with the Reverse Transcription Master premix kit (Elpis Bio, Daejeon, Korea), and the mixture was incubated for $60 \mathrm{~min}$ at $37^{\circ} \mathrm{C}$. The transcribed products were mixed with each primer set and GoTaq DNA polymerase (Promega, Madison, WI, USA) and were amplified in a PCR machine (Takara Bio). The primer sequences were as follows: IL-13 sense (5'-GAGTGTG TTTGTCACCGTTG-3') and antisense (5'-TACTCGTT GGTCGAGAGCTG-3'); GAPDH sense (5'-CATGAGAA GTATGACAACAGCCT-3') and antisense (5'-AGTCC TTCCACGATACCAAAGT- $\left.3^{\prime}\right)$. The PCR conditions for $I L-13$ and GAPDH were as follows: denaturation at $95^{\circ} \mathrm{C}$ for $30 \mathrm{~s}$, annealing at $56^{\circ} \mathrm{C}$ for $30 \mathrm{~s}$, and extension at $72^{\circ} \mathrm{C}$ for $40 \mathrm{~s}$ ( 35 cycles and 26 cycles). PCR products were analyzed on a $1.5 \%$ agarose gel. For real-time PCR, an aliquot of $1 \mu \mathrm{l}$ of cDNA was amplified in duplicate in a final volume of $20 \mu \mathrm{l}$ using the SensiFAST ${ }^{\mathrm{sx}} \mathrm{SYBR}^{\circledR}$ NOROX Kit (Bioline, London, UK). The thermocycling conditions were $95^{\circ} \mathrm{C}$ for $10 \mathrm{~min}$, followed by 40 cycles of $95^{\circ} \mathrm{C}$ for $15 \mathrm{~s}$ and $56^{\circ} \mathrm{C}$ for $1 \mathrm{~min}$. The primer sequences for real-time PCR were the same as those for RT-PCR.

\section{ELISA}

Cell supernatants were collected after $\operatorname{Der} f 2$ treatment, and the concentrations of IL-13 were measured using a commercial ELISA kit (Bender Medsystems, Vienna, Austria) following the manufacturer's instructions. The concentrations of samples were determined from a standard curve ranging from 3.13 to $200 \mathrm{pg} / \mathrm{ml}$. For mouse experiments, lung tissues were homogenized in $20 \mathrm{ml} / \mathrm{g}$ tissue protein extraction reagent (ThermoFisher, Rockford, IL, USA) using a tissue homogenizer (Biospec Products, Bartlesville, OK, USA). Homogenates were incubated at $4{ }^{\circ} \mathrm{C}$ for $30 \mathrm{~min}$ and centrifuged at $1000 \times g$ for $10 \mathrm{~min}$. The supernatants were collected and passed through a 0.45-micron filter (Gelman Sciences, Ann Arbor, MI, USA) for the measurement of cytokine levels.

\section{Cell viability}

Cells were incubated with MTT (3-(4,5-dimethylthiazol-2-yl)-2,5-diphenyltetrazolium bromide; Duchefa, Haarlem, Netherlands) solution at $37^{\circ} \mathrm{C}$ for $4 \mathrm{~h}$. Dark brown formazan crystals formed after the reduction of tetrazolium by the mitochondria of living cells dissolved in DMSO, and the optical densities were read at $570 \mathrm{~nm}$ with a microplate reader (BioRad, Hercules, CA, USA).

\section{Measurement of delivery efficiency}

Cells were plated onto coverslips in 24-well plates, and TAT-TVTSP-FAM (Supplementary Figure 2) was added for the indicated times. After removal of the medium, the cells were fixed with $4 \%$ PFA (Sigma-Aldrich, St. Louis, MO, USA) for $15 \mathrm{~min}$. The medium was replaced by $0.1 \%$ BSA in PBS, and the cells were mounted on slides with
Vectashield (DAKO, Glostrup, Denmark). FAM signals were photographed using a fluorescence microscope (Leica Microsystems, Wetzlar, Germany). The tissue permeability of TAT-TVTSP was also examined in a mouse model. Five-week-old female mice habituated for 1 week were intranasally administered TAT-TVTSP-FAM or saline. The tracheas and bronchioles were excised $2 \mathrm{~h}$ later and were immediately frozen in optimal cutting temperature (OCT) compound (Sakura Finetek, Torrance, CA, USA) and sectioned at a thickness of $10 \mu \mathrm{m}$. The sections were fixed with 4\% PFA for $15 \mathrm{~min}$, washed with $0.1 \%$ BSA in PBS, and mounted with Vectashield. Intracellular fluorescence signals were observed using a fluorescence microscope.

\section{Animals}

Female 6-week-old BALB/c mice (Orient, Gyeonggi-do, Korea) were used to generate the mouse model of allergic airway inflammation. For the in vivo toxicity studies, male and female 5-week-old ICR mice (Koathech, Gyeonggi-do, Korea) were used. They were maintained under specific pathogen-free conditions, fulfilling the standards of facilities approved by the American Association for the Accreditation of Laboratory Animal Care. All animal experiments were performed in accordance with the Korean Food and Drug Administration guidelines.

\section{Mouse model of allergic airway inflammation}

The protocols were reviewed and approved by the Institutional Animal Care and Use Committee of Hanyang Laboratory Animal Research Center (20150197A). The mice were assigned to the saline, $\operatorname{Der} f 2$, Der $f 2+$ TAT or $\operatorname{Der} f 2+$ TAT-TVTSP groups. As shown in Fig. 2a, TAT or TAT-TVTSP was administered intranasally $2 \mathrm{~h}$ prior to the intranasal injection of $\operatorname{Der} f 2(1.2$ $\mathrm{mg} / \mathrm{kg}$ ), and this was repeated 7 times over 2 weeks.

\section{Histology}

Lung tissues were fixed in 10\% formalin, embedded in paraffin, and sectioned. Sections were counterstained with H\&E or PAS for histological examination using standard techniques. After staining, the slides were rinsed in distilled water, mounted with Vectashield, and photographed using an optical microscope (Olympus, Tokyo, Japan).

\section{AHR measurement}

Airway hyperresponsiveness (AHR) was measured using a whole-body plethysmographic chamber (OCP-3000; Allmedicus, Gyeonggi-do, Korea). The mice were exposed to the indicated concentrations of methacholine (SigmaAldrich) using an ultrasonic nebulizer (Omron Healthcare, Kyoto, Japan). After placing the mouse in the chamber, airway responsiveness was measured by evaluating enhanced pause (Penh). Penh, as an index of airway 


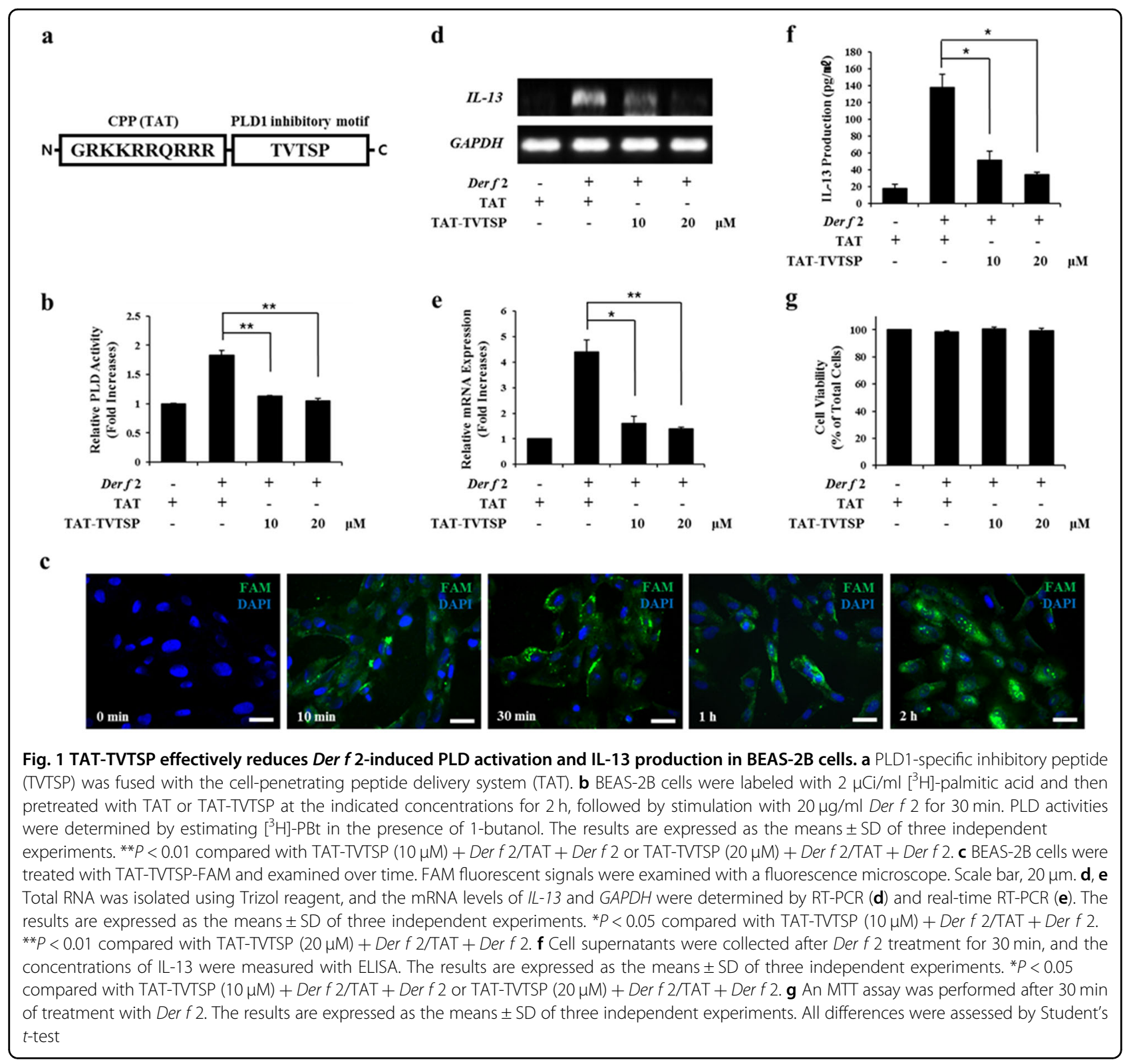

hyperresponsiveness, was calculated as previously described $^{35}$.

\section{BALF assay}

Bronchoalveolar lavage fluid (BALF) was obtained as previously described ${ }^{36}$. Lungs were lavaged with $1 \mathrm{ml}$ of Hank's balanced salt solution via a tracheostomy tube. The total cell numbers were counted using a hemocytometer (Sigma-Aldrich). BALF was then centrifuged at $1500 \times g$ for $3 \mathrm{~min}$ at $4{ }^{\circ} \mathrm{C}$, and smears of BAL cells were prepared by cytocentrifugation (Cytospin3; Thermo, Billerica, MA, USA) at $1000 \mathrm{rpm}$ for $3 \mathrm{~min}$. BAL cells were stained using a Hemacolor Staining Kit (Merck,
Darmstadt, Germany), counted and classified as neutrophils, eosinophils, lymphocytes, or macrophages.

\section{Single-dose toxicity study}

Protocols were reviewed and approved by the Institutional Animal Care and Use Committee of Hanyang Laboratory Animal Research Center (2016-0038A). Forty animals aged 5 weeks were randomly assigned to four different dose groups (Supplementary Table 1), and each concentration of TAT-TVTSP was injected intranasally. Changes in the clinical signs, body weight, and blood analysis indices were evaluated. All the animals were euthanized on day 14, except for four mice that had to be sacrificed earlier. Mortality was recorded, and tissues from 
the heart, kidney, liver, stomach, spleen, lung, intestine, and brain were collected for immediate necropsy. After fixation, organs sampled for histology were stained with $H \& E$ according to the standard procedures. In addition, blood samples were freshly drawn from each heart and were analyzed at the Korea Conformity Laboratories (Incheon, Korea). The following standard hematology markers were analyzed: red blood cell count, hemoglobin, hematocrit, mean corpuscle volume, mean corpuscle hemoglobin concentration, platelet count, and white blood cell count. Additionally, blood samples were centrifuged twice at $3000 \mathrm{rpm}$ for $10 \mathrm{~min}$ to separate sera. Liver function was evaluated from the serum levels of total bilirubin (T-BIL) and alkaline phosphatase (ALP). Albumin (ALB) was assayed as a measure of tissue damage or inflammation. Gamma glutamyl transferase (GGT) and total protein (TP) were also quantified. These parameters were determined using a Biochemical Autoanalyzer (Type 7170; Hitachi, Japan).

\section{Repeated-dose toxicity study}

Protocols were reviewed and approved by the Institution Animal Care and Use Committee of the Hanyang Laboratory Animal Research Center (2016-0038A). Forty animals (20 males and 20 females) were randomly allocated to four different dose groups (Supplementary Table 1). TAT-TVTSP (or saline) was administered intranasally every day for 4 weeks. Other procedures were similar to those in the "Single-dose toxicity study" section.

\section{Statistics}

Statistical analysis for a complex sampling design was performed using SPSS software, version 18.0 (SPSS Inc., Chicago, IL, USA). The data are expressed as the means \pm SD of at least three independent experiments; $P<0.05$ was considered statistically significant. Comparisons between groups were made using unpaired Student's $t$-tests, and multi-group comparisons of means were carried out by one-way repeated-measures analysis of variance (ANOVA).

\section{Results}

TAT-TVTSP is efficiently delivered into BEAS-2B cells and reduces Der $f$ 2-induced PLD activation and IL-13 production

We investigated whether a peptide in the PLD1-specific binding motif of AP180 was applicable as an inhibitor of airway inflammation induced by the house dust mite allergen $\operatorname{Der} f 2$. As shown in Fig. 1a, we designed a PLD1inhibitory peptide (TVTSP) coupled with TAT as a delivery vehicle. To verify whether this peptide (TATTVTSP) regulated PLD activity, human bronchial epithelial cells (BEAS-2B) were exposed to $\operatorname{Der} f 2(20 \mu \mathrm{g} / \mathrm{ml})$ for $30 \mathrm{~min}$ after pretreatment with TAT-TVTSP $(10$ or 20 $\mu \mathrm{M})$ or TAT $(10 \mu \mathrm{M})$ for 2 h. Der $f 2$-induced PLD activation was repressed by TAT-TVTSP in a dosedependent manner (Fig. 1b). Moreover, as shown in Supplementary Figure 1, TAT-TVTSP efficiently decreased $\operatorname{Der} f 2$-induced PLD activation compared with excess treatment $(50 \mu \mathrm{M})$ or Lipofectamine-mediated transfection of TVTSP, indicating that TAT powerfully acted as a transcellular delivery cargo. To further examine the efficiency of delivery of TAT-TVTSP, we labeled its Cterminus with the fluorescent dye FAM (Supplementary Figure 2) and measured the intracellular fluorescence over a time course. Green fluorescence was detected in almost all cells $1 \mathrm{~h}$ after exposure to TAT-TVTSP-FAM, and the signals were strongest after $2 \mathrm{~h}$ (Fig. 1c). Next, we found that $\operatorname{Der} f$ 2-induced IL-13 mRNA expression was significantly reduced by TAT-TVTSP (Fig. 1d, e), and the same was true for IL-13 production itself (Fig. 1f). Moreover, exposure to TAT-TVTSP had no effect on cell viability (Fig. 1g). Interestingly, the inhibitory effect of TAT-TVTSP on IL-13 expression was similar to that of other PLD inhibitors, FIPI and VU0155069 (Supplementary Figure 3). In summary, TAT-TVTSP was efficiently delivered into bronchial epithelial cells and reduced $\operatorname{Der} f$ 2-induced PLD activation and IL-13 production without any cytotoxicity.

\section{Intranasally administered TAT-TVTSP is efficiently transferred into airway tissues and blocks airway inflammation in a mouse model of Der $f$ 2-induced acute allergic asthma \\ To confirm whether TAT-TVTSP was also effective} in vivo, we made a HDM-induced airway inflammation mouse model of acute allergic asthma ${ }^{8}$. Female 6-weekold mice were intranasally injected with TAT or TATTVTSP $(10 \mathrm{mg} / \mathrm{kg})$ for $2 \mathrm{~h}$ prior to the administration of $\operatorname{Der} f 2(1.2 \mathrm{mg} / \mathrm{kg})$, and this was repeated 7 times over 2 weeks (Fig. 2a). We first assessed the delivery efficiency of TAT-TVTSP to target tissues by analyzing in vivo FAM fluorescence $2 \mathrm{~h}$ after intranasal injection of TATTVTSP-FAM. Considerable accumulation of green fluorescence was observed in both bronchioles and tracheas (Fig. 2b). Next, we investigated whether TATTVTSP affected airway inflammation in vivo. Lung histology was examined to evaluate the extent of inflammation, epithelial hyperplasia, and mucus secretion by goblet cells in airway tissues. As shown in Fig. 2c, after the injection of TAT (or saline), the intranasal administration of $\operatorname{Der} f 2$ stimulated the infiltration of peribronchial inflammatory cells, resulting in thickening of the airway tissues as well as increased secretion of mucus around the bronchial airways. Remarkably, these effects were prevented by intranasal challenge with TAT-TVTSP. Moreover, compared with pretreatment with TAT (or saline), TAT-TVTSP almost completely blocked $\operatorname{Der} f$ 2-induced 


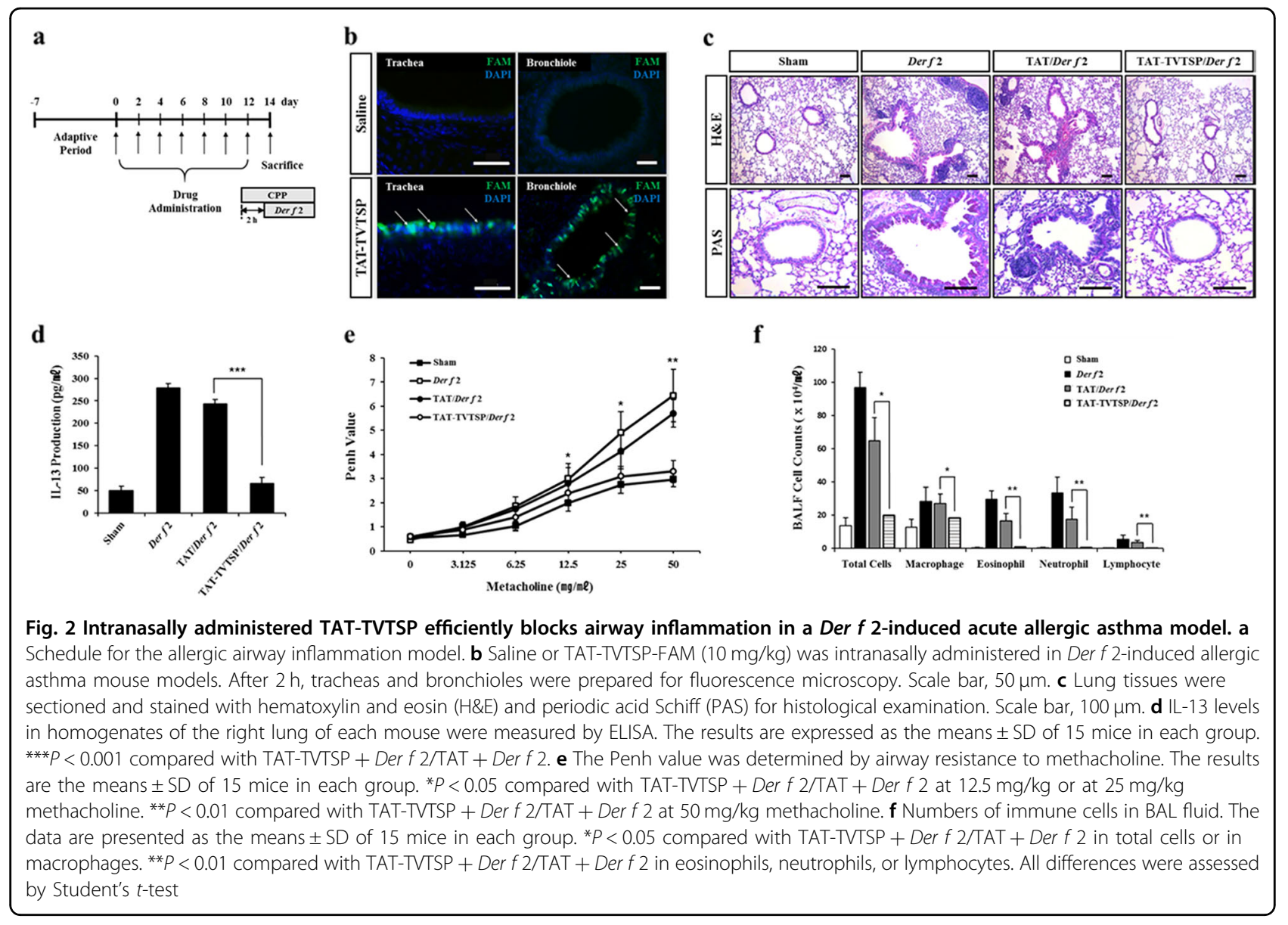

IL-13 production (Fig. 2d). We also evaluated airway hyperresponsiveness (AHR) by analyzing lung resistance to methacholine (Fig. 2e). Intranasal administration of TAT-TVTSP substantially attenuated $\operatorname{Der} f$ 2-developed AHR to nebulized methacholine, implying that it blocked allergic inflammation and AHR. The number of immune cells in BALFs was also significantly decreased by TATTVTSP (Fig. 2f). Taken together, we conclude that targeting of PLD1 with TAT-TVTSP has powerful antiinflammatory effects on the $\operatorname{Der} f 2$-induced allergic airway inflammation model and may be an effective therapeutic for allergic diseases, including asthma.

\section{Single-dose toxicity study}

We next investigated whether TAT-TVTSP is clinically applicable as a novel anti-asthmatic agent. In the doseprobing pilot study for the toxicity test, 3 mice in the 250 $\mathrm{mg} / \mathrm{kg}$ group, 5 in the $500 \mathrm{mg} / \mathrm{kg}$ group, and 7 in the 1000 $\mathrm{mg} / \mathrm{kg}$ group died, indicating that the median lethal dose $\left(\mathrm{LD}_{50}\right)$ of TAT-TVTSP was $453.8 \mathrm{mg} / \mathrm{kg}$, when calculated by the Behrens-Kärber method (Supplementary Figure 4 and Fig. 3a). In addition, 6 mice (3 male and 3 female animals) were challenged with TAT $(1000 \mathrm{mg} / \mathrm{kg})$. Two of these ( 1 male and 1 female) died on day 0 . At full necropsy, we found that they had suffocated to death, indicating that intranasal administration caused serious stress. However, the 4 remaining mice showed no any abnormal behavior, and all survived to day 14, implying that TAT is not harmful per se (data not shown).

Based on this pilot study, a single-dose toxicity study was conducted (Fig. 3b). At 14 days after exposure, there was less body-weight gain in the TAT-TVTSP-treated groups than in the control group (Supplementary Table 2). In the low-dose groups, 2 of the 5 female mice had several symptoms such as loss of appetite, no stool, crouching and lacrimation, while the 5 males displayed no abnormal behavior, and all survived. Of two females in this group, one showed symptoms, including alopecia, crouching, edema, and gasping behavior on day 4 and was dead by day 6 . Another mouse also had the same symptoms on days 8-11 and died on day 12 . In the mediumdose groups, none of the animals had abnormal behavior, and all survived to day 14 . In the high-dose groups, 5 (2 male and 3 female) of the 10 mice showed appetite loss and gasping on day 1 . Two of them (1 male and 1 female) had serious symptoms, including lacrimation, edema, and 


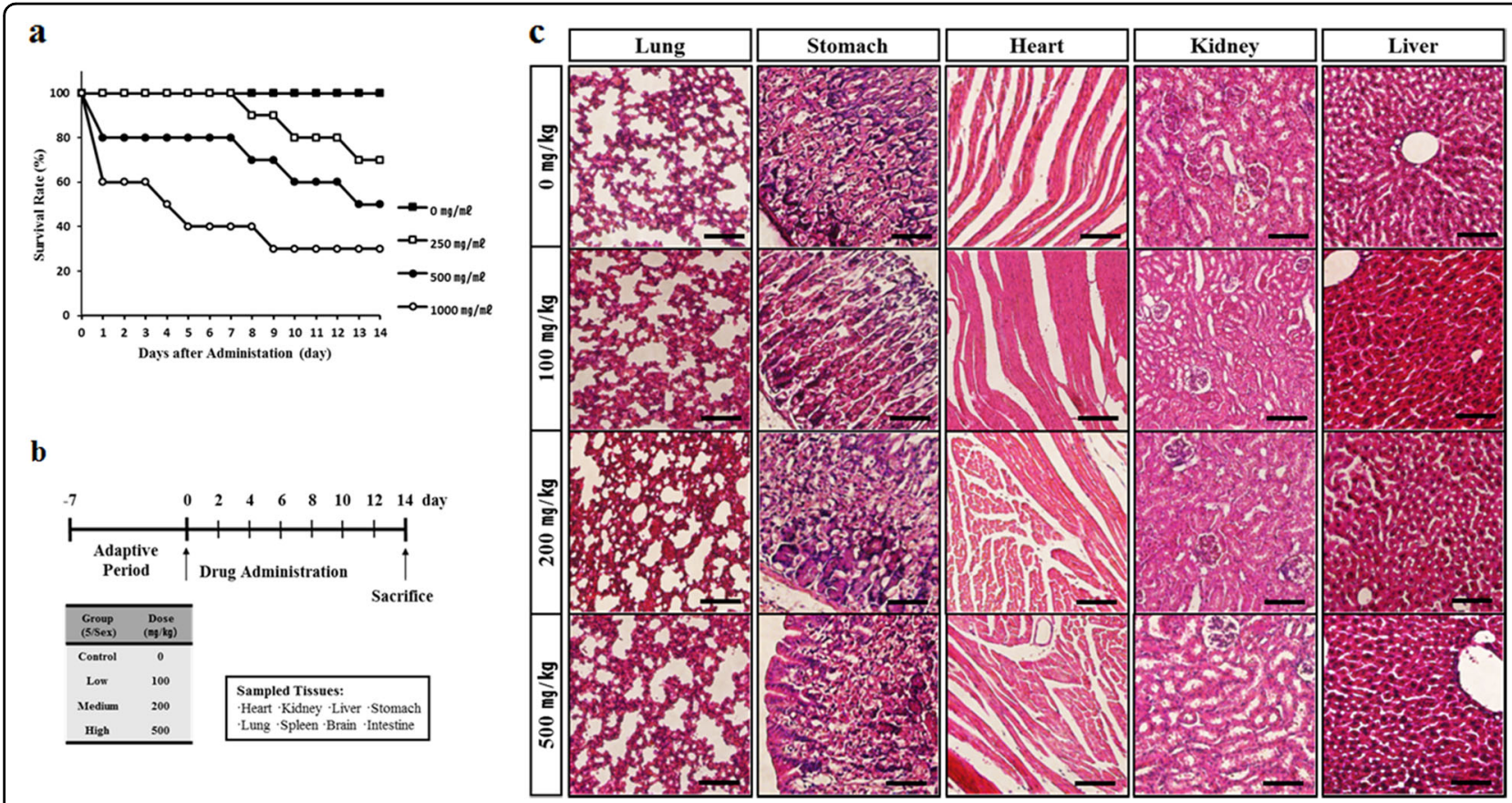

Fig. 3 Single-dose toxicity study. a Preliminary study for dose selection. b Schedule for the single-dose toxicity test. c After 14 days, fixed organ samples were dehydrated, paraffinized, and embedded. Sections of $4 \mu \mathrm{m}$ were stained with H\&E and examined by microscopy. Scale bar, $100 \mu \mathrm{m}$

Table 1 Biochemical analysis of sera of male and female mice in the single dose toxicity test

\begin{tabular}{|c|c|c|c|c|c|c|c|c|}
\hline \multirow[t]{3}{*}{ Test item } & \multicolumn{4}{|l|}{ Male } & \multicolumn{4}{|l|}{ Female } \\
\hline & Control & Low & Medium & High & Control & Low & Medium & High \\
\hline & $0 \mathrm{mg} / \mathrm{kg}$ & $100 \mathrm{mg} / \mathrm{kg}$ & $200 \mathrm{mg} / \mathrm{kg}$ & $500 \mathrm{mg} / \mathrm{kg}$ & $0 \mathrm{mg} / \mathrm{kg}$ & $100 \mathrm{mg} / \mathrm{kg}$ & $200 \mathrm{mg} / \mathrm{kg}$ & $500 \mathrm{mg} / \mathrm{kg}$ \\
\hline ALB (IU/I) & $1.78 \pm 0.02$ & $1.80 \pm 0.03$ & $1.78 \pm 0.06$ & $1.70 \pm 0.06$ & $1.32 \pm 0.16$ & $1.57 \pm 0.23$ & $1.43 \pm 0.01$ & $1.35 \pm 0.09$ \\
\hline ALP (IU/I) & $262.00 \pm 56.45$ & $221.40 \pm 22.83$ & $233.20 \pm 24.95$ & $249.50 \pm 12.99$ & $229.00 \pm 31.95$ & $307.00 \pm 43.02$ & $275.00 \pm 23.23$ & $258.00 \pm 31.65$ \\
\hline GGT (IU/I) & $0.00 \pm 0.00$ & $0.00 \pm 0.00$ & $0.00 \pm 0.00$ & $0.00 \pm 0.00$ & $0.00 \pm 0.00$ & $0.00 \pm 0.00$ & $0.00 \pm 0.00$ & $0.00 \pm 0.00$ \\
\hline TP (IU/I) & $5.38 \pm 0.04$ & $5.38 \pm 0.09$ & $5.30 \pm 0.2$ & $5.00 \pm 0.2$ & $4.00 \pm 0.49$ & $4.77 \pm 0.74$ & $4.25 \pm 0.09$ & $3.80 \pm 0.30$ \\
\hline T-BIL (IU/I) & $0.10 \pm 0.02$ & $0.09 \pm 0.01$ & $0.11 \pm 0.02$ & $0.11 \pm 0.02$ & $0.01 \pm 0.01$ & $0.06 \pm 0.06$ & $0.03 \pm 0.01$ & $0.01 \pm 0.01$ \\
\hline
\end{tabular}

Data are expressed as means \pm SD ( $n=5$ per each group). Differences were assessed by one-way ANOVA

$A L B$ albumin, $A L P$ alanine aminotransferase, GGT gamma $(\gamma)$-glutamyl transferase, $T P$ total protein, $T$-BIL total bilirubin

gasping; the female died on day 5 , and the male died on day 13 (Supplementary Table 3). Next, blood samples obtained from each mouse were analyzed in detail for serum chemistry and hematology parameters. As shown in Table 1, the serum levels of measured factors were within normal ranges and showed no significant difference. Moreover, the hematological parameters did not change significantly, although the platelet (PLT) levels appeared to rise slightly in female mice, and white blood cell (WBC) and eosinophil (EOS) levels tended to fall with increasing dose (Table 2). Finally, histopathological analysis was conducted by microscopic observation of each tissue in detail. As shown in Fig. 3c, the lungs, as well as other observed organs, did not undergo any change in appearance and micro-morphology in any of the TATTVTSP groups.

\section{Repeated-dose toxicity study}

Based on the single-dose toxicology study and examination of in vivo airway inflammation, we investigated the toxicity of repeated intranasal administration of TATTVTSP (Fig. 4a). All the TAT-TVTSP-treated female groups showed a tendency to gain a little less weight than the control group, whereas all the male groups gained weight similar to the saline group (Supplementary Table 4). None of the animals showed any clinical manifestations, and all survived to day 28 (Supplementary Table 5). Moreover, the weights of the liver, lung, spleen, 
Table 2 Hematological analysis for male and female mice in single dose toxicity study

\begin{tabular}{|c|c|c|c|c|c|c|c|c|}
\hline \multirow[t]{3}{*}{ Test item } & \multicolumn{4}{|l|}{ Male } & \multicolumn{4}{|l|}{ Female } \\
\hline & Control & Low & Medium & High & Control & Low & Medium & High \\
\hline & $0 \mathrm{mg} / \mathrm{kg}$ & $100 \mathrm{mg} / \mathrm{kg}$ & $200 \mathrm{mg} / \mathrm{kg}$ & $500 \mathrm{mg} / \mathrm{kg}$ & $0 \mathrm{mg} / \mathrm{kg}$ & $100 \mathrm{mg} / \mathrm{kg}$ & $200 \mathrm{mg} / \mathrm{kg}$ & $500 \mathrm{mg} / \mathrm{kg}$ \\
\hline WBC $\left(\times 10^{3} \mathrm{cell} / \mu \mathrm{l}\right)$ & $5.55 \pm 3.76$ & $3.34 \pm 1.32$ & $3.70 \pm 1.53$ & $3.69 \pm 1.20$ & $4.25 \pm 1.39$ & $2.83 \pm 0.52$ & $3.37 \pm 0.98$ & $2.18 \pm 1.20$ \\
\hline $\mathrm{RBC}\left(\times 10^{3} \mathrm{cell} / \mu \mathrm{l}\right)$ & $9.25 \pm 0.21$ & $9.35 \pm 0.73$ & $9.19 \pm 0.27$ & $9.10 \pm 0.58$ & $7.95 \pm 0.83$ & $8.36 \pm 0.23$ & $8.27 \pm 0.47$ & $7.84 \pm 0.80$ \\
\hline HGB $(g / l)$ & $153.20 \pm 0.03$ & $150.00 \pm 0.06$ & $149.20 \pm 0.04$ & $145.50 \pm 0.07$ & $134.00 \pm 0.13$ & $137.00 \pm 0.01$ & $137.30 \pm 0.05$ & $124.80 \pm 0.14$ \\
\hline HCT (\%) & $50.32 \pm 1.19$ & $49.86 \pm 3.06$ & $49.16 \pm 0.93$ & $48.18 \pm 1.81$ & $43.45 \pm 3.32$ & $45.10 \pm 0.14$ & $43.93 \pm 2.20$ & $40.30 \pm 4.50$ \\
\hline MCV (fl) & $54.45 \pm 0.88$ & $53.36 \pm 1.63$ & $53.48 \pm 1.27$ & $53.08 \pm 1.64$ & $54.75 \pm 1.49$ & $54.15 \pm 1.63$ & $53.15 \pm 1.03$ & $51.4 \pm 0.77$ \\
\hline $\mathrm{MCH}(\mathrm{pg})$ & $16.62 \pm 0.31$ & $16.04 \pm 0.63$ & $16.24 \pm 0.52$ & $15.98 \pm 0.39$ & $16.85 \pm 0.07$ & $16.4 \pm 0.28$ & $16.6 \pm 0.62$ & $15.9 \pm 0.54$ \\
\hline $\mathrm{MCHC}(\mathrm{g} / \mathrm{l})$ & $304.60 \pm 0.43$ & $300.60 \pm 1.02$ & $303.80 \pm 0.61$ & $301.50 \pm 0.42$ & $307.50 \pm 0.64$ & $302.50 \pm 0.35$ & $312.30 \pm 0.88$ & $309.50 \pm 0.87$ \\
\hline RDW (\%) & $11.38 \pm 0.54$ & $11.56 \pm 0.30$ & $11.30 \pm 0.51$ & $11.10 \pm 0.47$ & $12.20 \pm 0.10$ & $12.20 \pm 0.42$ & $12.08 \pm 0.45$ & $12.18 \pm 0.55$ \\
\hline PLT $\left(\times 10^{3} \mathrm{cell} / \mu \mathrm{l}\right)$ & $1140 \pm 162.70$ & $1402 \pm 268.60$ & $1391 \pm 307.20$ & $1588 \pm 174.60$ & $788 \pm 67.88$ & $788 \pm 135.80$ & $769 \pm 266.30$ & $619.5 \pm 378.10$ \\
\hline MPV (fl) & $4.98 \pm 0.25$ & $4.74 \pm 0.35$ & $4.66 \pm 0.37$ & $4.48 \pm 0.13$ & $5.60 \pm 0.70$ & $6.25 \pm 0.50$ & $5.65 \pm 0.49$ & $6.53 \pm 1.59$ \\
\hline NEUT (\%) & $16.36 \pm 4.70$ & $23.02 \pm 6.07$ & $21.6 \pm 6.97$ & $18.4 \pm 5.47$ & $17.05 \pm 3.61$ & $12.75 \pm 1.49$ & $10.50 \pm 2.80$ & $20.20 \pm 8.69$ \\
\hline LYM (\%) & $72.88 \pm 10.15$ & $67.94 \pm 6.45$ & $69.28 \pm 10.30$ & $74.48 \pm 6.17$ & $66.80 \pm 4.67$ & $56.25 \pm 3.75$ & $72.30 \pm 10.52$ & $56.03 \pm 8.27$ \\
\hline MONO (\%) & $0.84 \pm 0.38$ & $0.80 \pm 0.22$ & $0.82 \pm 0.36$ & $0.68 \pm 0.24$ & $0.70 \pm 0.14$ & $0.80 \pm 0.28$ & $0.43 \pm 0.25$ & $1.10 \pm 0.42$ \\
\hline EOS (\%) & $8.76 \pm 5.89$ & $7.34 \pm 2.83$ & $7.64 \pm 5.56$ & $5.33 \pm 3.32$ & $14.2 \pm 8.49$ & $29.05 \pm 5.45$ & $15.88 \pm 12.22$ & $17.65 \pm 7.78$ \\
\hline LUC (\%) & $0.88 \pm 0.77$ & $0.74 \pm 0.29$ & $0.62 \pm 0.26$ & $0.88 \pm 0.21$ & $0.80 \pm 0.14$ & $0.75 \pm 0.21$ & $0.65 \pm 0.54$ & $4.85 \pm 7.80$ \\
\hline BASO (\%) & $0.28 \pm 0.38$ & $0.20 \pm 0.19$ & $0.24 \pm 0.18$ & $0.28 \pm 0.31$ & $0.45 \pm 0.21$ & $0.40 \pm 0.14$ & $0.25 \pm 0.31$ & $0.43 \pm 0.43$ \\
\hline NEUT $\left(\times 10^{3}\right.$ cell/ $\left./ \mu \mathrm{l}\right)$ & $0.77 \pm 0.20$ & $0.72 \pm 0.26$ & $0.72 \pm 0.13$ & $0.67 \pm 0.27$ & $0.75 \pm 0.40$ & $0.37 \pm 0.11$ & $0.35 \pm 0.10$ & $0.44 \pm 0.28$ \\
\hline 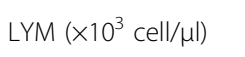 & $4.30 \pm 3.56$ & $2.32 \pm 1.04$ & $2.68 \pm 1.49$ & $2.79 \pm 1.07$ & $2.87 \pm 1.13$ & $1.61 \pm 0.40$ & $2.50 \pm 0.96$ & $1.21 \pm 0.74$ \\
\hline MONO $\left(\times 10^{3}\right.$ cell $\left./ \mu \mathrm{l}\right)$ & $0.04 \pm 0.03$ & $0.03 \pm 0.01$ & $0.03 \pm 0.02$ & $0.03 \pm 0.01$ & $0.03 \pm 0.01$ & $0.03 \pm 0.01$ & $0.02 \pm 0.01$ & $0.02 \pm 0.01$ \\
\hline $\operatorname{EOS}\left(\times 10^{3} \mathrm{cell} / \mu \mathrm{l}\right)$ & $0.36 \pm 0.18$ & $0.24 \pm 0.15$ & $0.23 \pm 0.08$ & $0.17 \pm 0.03$ & $0.55 \pm 0.16$ & $0.81 \pm 0.00$ & $0.48 \pm 0.26$ & $0.41 \pm 0.31$ \\
\hline LUC $\left(\times 10^{3}\right.$ cell/ $\left./ \mathrm{l}\right)$ & $0.07 \pm 0.11$ & $0.03 \pm 0.01$ & $0.02 \pm 0.02$ & $0.04 \pm 0.01$ & $0.03 \pm 0.00$ & $0.02 \pm 0.00$ & $0.02 \pm 0.02$ & $0.07 \pm 0.11$ \\
\hline BASO $\left(\times 10^{3}\right.$ cell/ $\left.\mu \mathrm{l}\right)$ & $0.01 \pm 0.01$ & $0.01 \pm 0.01$ & $0.01 \pm 0.00$ & $0.01 \pm 0.00$ & $0.02 \pm 0.01$ & $0.02 \pm 0.01$ & $0.01 \pm 0.01$ & $0.01 \pm 0.01$ \\
\hline Retic (\%) & $3.28 \pm 0.83$ & $2.30 \pm 0.51$ & $2.63 \pm 0.51$ & $2.54 \pm 0.43$ & $3.62 \pm 2.52$ & $2.17 \pm 0.33$ & $3.19 \pm 0.65$ & $3.02 \pm 0.63$ \\
\hline
\end{tabular}

Data are expressed as means \pm SD ( $n=5$ per each group). Differences were assessed by one-way ANOVA

WBC white blood cell, $R B C$ red blood cell, HGB hemoglobin, $H C T$ hematocrit, $M C V$ mean corpuscular volume, $M C H$ mean corpuscular hemoglobin, $M C H C$ mean corpuscular hemoglobin concentration, RDW red blood cell distribution width, PLT platelet, MPV mean platelet volume, NEUT neutrophil, LYM lymphocyte, MONO monocyte, EOS eosinophil, LUC large unstained cell, BASO basophil, Retic reticulocyte

kidney, stomach, and heart were not affected in any of the TAT-TVTSP-treated groups (Fig. 4b and Supplementary Table 6). However, the brain weight in the high-dose group was significantly reduced compared with that in the control group (Fig. 4b). Intranasal injection is frequently used for the delivery of drugs into brain tissues, and PLD1 was previously reported as an important mediator of neurogenesis in brain tissues such as the hippocampus and cortex ${ }^{12,37}$. Therefore, it might be anticipated that repeated intranasal injection of TAT-TVTSP would have some effect on brain development by suppressing PLD1. Finally, histological analysis was conducted by microscopic observation of each tissue, and no organs were affected in the TAT-TVTSP-treated groups (Fig. 4c).

\section{Discussion}

Asthma is a chronic lung disease characterized by airway inflammation, airflow obstruction, and airway hyperresponsiveness ${ }^{1}$. Allergic diseases, including asthma, are generally caused by individual genetic factors and are aggravated by environmental insults ${ }^{1}$. House dust mites are the major inhalant allergens of chronic allergic diseases, including childhood asthma ${ }^{5,38}$. HDMs induce airway inflammation by stimulating the production of Th2 pro-inflammatory cytokines ${ }^{6,39}$. We previously demonstrated that PLD1 is activated in T lymphocytes of Dermatophagoides farinae-specific allergic patients ${ }^{40}$. Furthermore, we showed that $\operatorname{Der} f 2$ stimulated IL-13 production by activating PLD1 in human bronchial epithelial cells ${ }^{7,8}$, indicating that targeting PLD1 might 

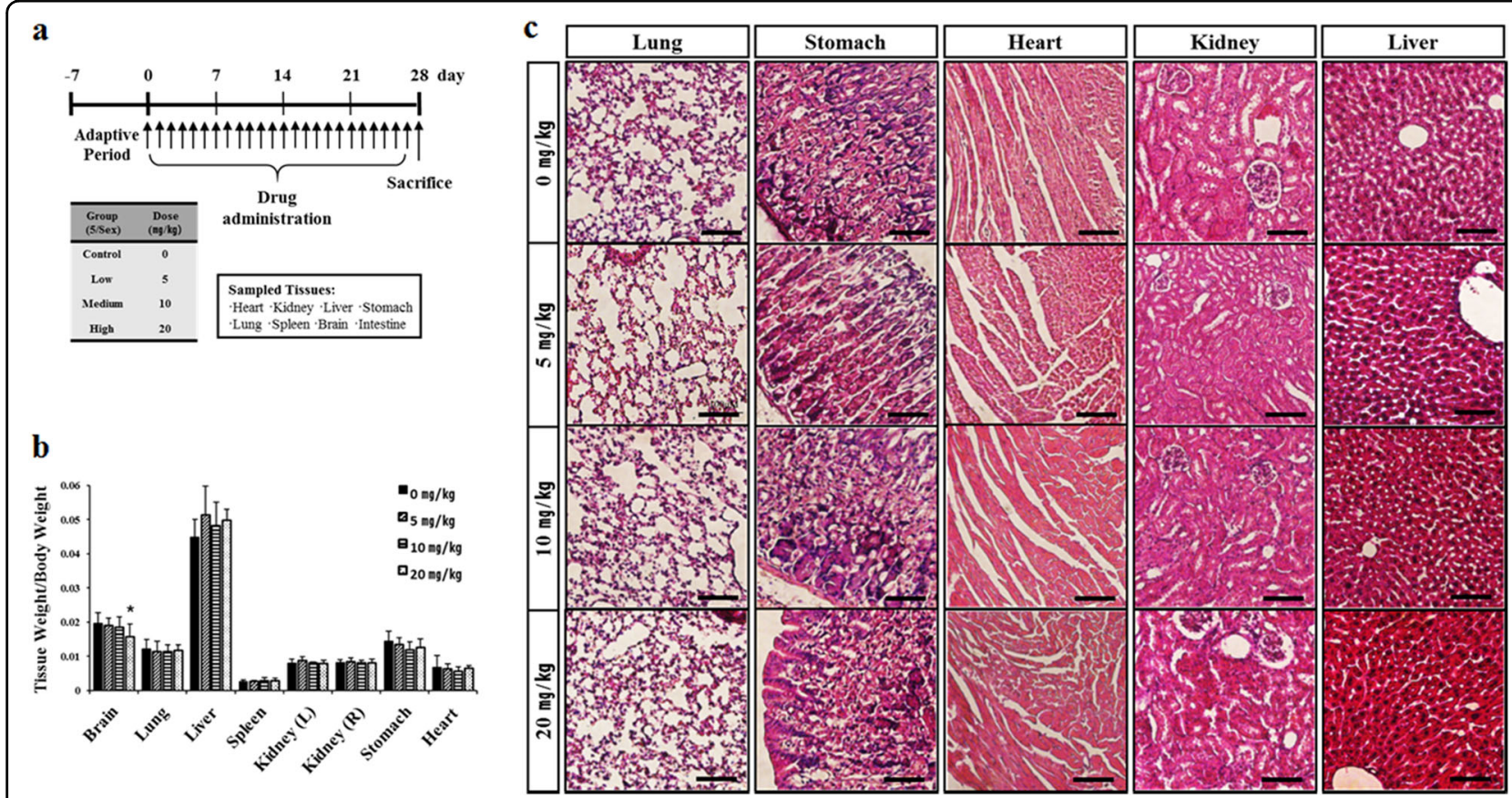

Fig. 4 Repeated-dose toxicity study. a Schedule for repeated-dose toxicity test of TAT-TVTSP. $\mathbf{b}$ The organs were weighed, and the values were expressed as the organ weight/body weight and presented as the means \pm SD of 10 mice per group. Differences were assessed by one-way ANOVA. * $P<0.05$ compared with the brain weight of the untreated control. c Fixed organ samples were dehydrated, paraffinized, and embedded. Sections of $4 \mu \mathrm{m}$ were stained with H\&E and observed under a microscope. Scale bar, $100 \mu \mathrm{m}$

suppress airway inflammation by inhibiting IL-13 expression. However, targeting of PLD1 can result in systemic adverse effects because PLD1 is involved in various biological processes. Therefore, topical targeting of PLD1 is extremely important to avoid the side effects.

PLD1 is an important enzyme responsible for the production of the lipid second messenger phosphatidic acid by catalyzing the hydrolysis of phospholipids ${ }^{9}$. Primary alcohols (for example, $n$-butanol) act as competitive nucleophiles to water, resulting in a transphosphatidylation to produce phosphatidylalcohols (for example, phosphatidylbutanol), instead of phosphatidic acid $^{18}$. Based on this principle, $n$-butanol has been used as a PLD inhibitor in various studies ${ }^{41}$, but it has several problems, such as indirect targeting, intracellular complementary systems, low efficiency, and side effects. Consequently, new specific PLD inhibitors need to be developed ${ }^{18}$. Several small-molecule PLD inhibitors have been shown to be effective in various diseases, but they also have limitations in terms of selectivity, side effects, and toxicity. In these circumstances, we recently developed a small peptide consisting of five amino acids that binds to and inactivates PLD1 ${ }^{23}$. However, the peptide may be quickly degraded by intracellular functions, including peptidase effects or autophagy ${ }^{42}$, and the delivery into cells or tissues can be limited by the lowpenetrating efficiency in crossing the cellular membrane.
These issues evoked the necessity for the appropriate topical targeting of PLD1 and application of efficient drug delivery systems. Therefore, we considered the utilization of a CPP as a delivery cargo and constructed TATTVTSP, a PLD1-specific inhibitory peptide fused with TAT. As expected, TAT-TVTSP was efficiently transferred into airway tissues and strongly suppressed $\operatorname{Der} f 2$ induced airway inflammation indices, indicating that it has powerful possibilities as an anti-asthma agent.

Although TAT was first regarded as a biologically inert vehicle, recent studies have reported that it can affect various cellular processes ${ }^{43}$. In HeLa cells, a TAT-derived peptide inhibited tumor necrosis factor-mediated signal transduction $^{44}$, and a microarray study revealed altered gene expression patterns after the application of HIV-1 $\mathrm{TAT}^{45}$. Moreover, in human lung epithelial cells, TAT modulated inflammatory responses by inhibiting the production of multiple cytokines and induced apoptosis ${ }^{46}$. However, despite these reports, TAT appeared to only act as a delivery vehicle in the present study. It was not cytotoxic, and the previously reported $\operatorname{Der} f 2$ effects, such as PLD activation and IL-13 upregulation in vitro, as well as bronchial inflammation stimulation in vivo, were faithfully reproduced (Figs. 1 and 2).

Toxicological analysis of a pro-drug is critical in evaluating its clinical potential. The general toxicity of drugs needs to be appraised through single- and repeated-dose 
experiments because toxicants may induce acute and chronic effects depending on the dose and duration of drug exposure. Therefore, we investigated the safety of TAT-TVTSP as a therapeutic agent through single- and repeated-dose toxicity test in a mouse model. The median lethal dose $\left(\mathrm{LD}_{50}\right)$ of TAT-TVTSP was calculated to be $\sim 450 \mathrm{mg} / \mathrm{kg}$. In the single-dose toxicology study, TAT-TVTSP induced acute toxicity, including the loss of body weight and several clinical signs (crouching and lacrimation). Nevertheless, we observed no statistically significant effects on hematology, serum biochemistry, and histopathology. In the repeated-dose toxicology study, TAT-TVTSP also did not display strong toxicity. However, the brain weight was significantly reduced in the high-dose group, suggesting that repeated intranasal injection of TAT-TVTSP might cause the suppression of brain functions via unexpected targeting. Further studies of the pharmacokinetics of TAT-TVTSP are required to address its unexpected brain targeting. Nonetheless, we may conclude that TAT-TVTSP as a novel and effective PLD1 inhibitor suppresses HDM-induced airway inflammation in vitro as well as in vivo. Furthermore, topical application of TAT-TVTSP as a novel inhaled antiasthmatic drug is expected to reduce the adverse effects that can be caused by the systemic inhibition of PLD.

\begin{abstract}
Acknowledgements
We thank Dr. Je-Min Choi (Hanyang University, Seoul, Republic of Korea) for the CPP design and Dr. Ju-Seop Kang (Hanyang University, Seoul, Republic of Korea) for helpful discussions on the entire toxicity study. This work was supported by the National Research Foundation of Korea (NRF) grants funded by the Korean government (MSIP) (NRF-2013R1A2A2A03067895 and NRF2016R1A2B4015358) and the Bio \& Medical Technology Development Program of the NRF funded by the Korean government, MSIP (2017M3A9D8063627).
\end{abstract}

\section{Author details}

1Department of Biomedical Sciences, Graduate School of Biomedical Science and Engineering, Hanyang University, Seoul 04763, Republic of Korea. ${ }^{2}$ Biomedical Research Institute and Department of Biochemistry and Molecular Biology, College of Medicine, Hanyang University, Seoul 04763, Republic of Korea. ${ }^{3}$ Department of Biochemistry and Signaling Disorder Research Center, College of Medicine, Chungbuk National University, Cheongju 28644, Republic of Korea

\section{Conflict of interest}

The authors declare that they have no conflict of interest.

\section{Publisher's note}

Springer Nature remains neutral with regard to jurisdictional claims inpublished maps and institutional affiliations.

Supplementary information accompanies this paper at https://doi.org/ 10.1038/s12276-018-0083-4.

Received: 10 January 2018 Revised: 12 February 2018 Accepted: 5 March 2018.

Published online: 1 May 2018

\section{References}

1. Holgate, S. T. Innate and adaptive immune responses in asthma. Nat. Med. 18 673-683 (2012)

2. Teixeira, H. M., Alcantara-Neves, N. M., Barreto, M., Figueiredo, C. A. \& Costa, R. S. Adenylyl cyclase type 9 gene polymorphisms are associated with asthma and allergy in Brazilian children. Mol. Immunol. 82, 137-145 (2017).

3. Heaney, L. G. \& Robinson, D. S. Severe asthma treatment: need for characterising patients. Lancet 365, 974-976 (2005).

4. Horne, R. Compliance, adherence, and concordance: implications for asthma treatment. Chest 130, 65S-72S (2006).

5. Gregory, L. G. \& Lloyd, C. M. Orchestrating house dust mite-associated allergy in the lung. Trends Immunol. 32, 402-411 (2011).

6. Shimizu, Y. S. M., Hiramatsu, K., Takeuchi, M., Nagai, H. \& Takagi, K. Mite antigeninduced IL-4 and IL-13 production by basophils derived from atopic asthma patients. Clin. Exp. Allergy 28, 497-503 (1998).

7. Park, S. Y. et al. House dust mite allergen Der $f$ 2-induced phospholipase D1 activation is critical for the production of interleukin-13 through activating transcription factor-2 activation in human bronchial epithelial cells. J. Biol. Chem. 284, 20099-20110 (2009).

8. Choi, H. J. et al. The TLR4-associated phospholipase D1 activation is crucial for Der $f$ 2-induced IL-13 production. Allergy 70, 1569-1579 (2015).

9. Billah, M. M. \& Anthes, J. C. The regulation and cellular functions of phosphatidylcholine hydrolysis. Biochem. J. 269, 281-291 (1990).

10. Roth, M. G. Molecular mechanisms of PLD function in membrane traffic. Traffic 9, 1233-1239 (2008)

11. Fang, Y. et al. PLD1 regulates $m T O R$ signaling and mediates Cdc42 activation of S6K1. Curr. Biol. 13, 2037-2044 (2003).

12. Park, S. Y. et al. Hippocalcin promotes neuronal differentiation and inhibits astrocytic differentiation in neural stem cells. Stem Cell Rep. 8, 95-111 (2017).

13. Lee, S. Y., Lee, Y. Y., Choi, J. S., Yoon, M. S. \& Han, J. S. Phosphatidic acid induces decidualization by stimulating Akt-PP2A binding in human endometrial stromal cells. Febs. J. 283, 4163-4175 (2016).

14. Park, J. B. et al. Phospholipase signalling networks in cancer. Nat. Rev. Cancer 12, 782-792 (2012).

15. Shi, M., Zheng, Y., Garcia, A., Xu, L. \& Foster, D. A. Phospholipase D provides a survival signal in human cancer cells with activated $\mathrm{H}$-Ras or K-Ras. Cancer Lett. 258, 268-275 (2007).

16. Dall'Armi, C. et al. The phospholipase D1 pathway modulates macroautophagy. Nat. Commun. 1, 142 (2010).

17. Kang, D. W. et al. Targeting phospholipase D1 attenuates intestinal tumorigenesis by controlling beta-catenin signaling in cancer-initiating cells. J. Exp. Med. 212, 1219-1237 (2015).

18. Scott, S. A. et al. Design of isoform-selective phospholipase D inhibitors that modulate cancer cell invasiveness. Nat. Chem. Biol. 5, 108-117 (2009).

19. Su, W. et al. 5-Fluoro-2-indolyl des-chlorohalopemide (FIPI), a phospholipase D pharmacological inhibitor that alters cell spreading and inhibits chemotaxis. Mol. Pharmacol. 75, 437-446 (2009).

20. Liu, Y. et al. The role of phospholipase D in modulating the MTOR signaling pathway in polycystic kidney disease. PLOS ONE 8, e73173 (2013).

21. Lee, $C$. et al. Inhibition of phospholipase $D$ by clathrin assembly protein 3 (AP3). J. Biol. Chem. 272, 15986-15992 (1997).

22. Ford, M. G. et al. Simultaneous binding of Ptdlns(4,5)P2 and clathrin by AP180 in the nucleation of clathrin lattices on membranes. Science 291, 1051-1055 (2001).

23. Cho, J. H. et al. The TSP motif in AP180 inhibits phospholipase D1 activity resulting in increased efficacy of anticancer drug via its direct binding to carboxyl terminal of phospholipase D1. Cancer Lett. 302, 144-154 (2011).

24. Han, J. S., Oh, D. Y. \& Cho, J. H. Korea patent 101048799 (2011).

25. Han, J. S., Oh, D. Y. \& Cho, J. H. Korea patent 101190262 (2012).

26. Nagahara, H. et al. Transduction of full-length TAT fusion proteins into mammalian cells: TAT-p27Kip1 induces cell migration. Nat. Med. 4, 1449-1452 (1998).

27. Juliano, R. L., Alam, R., Dixit, V. \& Kang, H. M. Cell-targeting and cell-penetrating peptides for delivery of therapeutic and imaging agents. Wiley Interdiscip. Rev. Nanomed. Nanobiotechnol 1, 324-335 (2009).

28. Zhang, X., Zhang, X. \& Wang, F. Intracellular transduction and potential of Tat PTD and its analogs: from basic drug delivery mechanism to application. Expert. Opin. Drug. Deliv. 9, 457-472 (2012). 
29. Tao, F., Su, Q. \& Johns, R. A. Cell-permeable peptide Tat-PSD-95 PDZ2 inhibits chronic inflammatory pain behaviors in mice. Mol. Ther. 16, 1776-1782 (2008).

30. Denicourt, C. \& Dowdy, S. F. Protein transduction technology offers novel therapeutic approach for brain ischemia. Trends Pharmacol. Sci. 24, 216-218 (2003).

31. Tan, M. et al. Selective inhibition of ErbB2-overexpressing breast cancer in vivo by a novel TAT-based ErbB2-targeting signal transducers and activators of transcription 3-blocking peptide. Cancer Res. 66, 3764-3772 (2006).

32. Lee, S. H. et al. Anti-inflammatory effects of Tat-Annexin protein on ovalbumin-induced airway inflammation in a mouse model of asthma. Biochem. Biophys. Res. Commun. 417, 1024-1029 (2012).

33. van den Berg, A. \& Dowdy, S. F. Protein transduction domain delivery of therapeutic macromolecules. Curr. Opin. Biotechnol. 22, 888-893 (2011).

34. Bligh, E. G. \& Dyer, W. J. A rapid method of total lipid extraction and purification. Can. J. Biochem. Physiol. 37, 911-917 (1959).

35. Hamelmann, E. et al. Noninvasive measurement of airway responsiveness in allergic mice using barometric plethysmography. Am. J. Respir. Crit. Care Med. 156, 766-775 (1997).

36. Gribar, S. C., Anand, R. J., Sodhi, C. P. \& Hackam, D. J. The role of epithelial Tolllike receptor signaling in the pathogenesis of intestinal inflammation. J. Leukoc. Biol. 83, 493-498 (2008).

37. Park, S. Y., Ma, W., Yoon, S. N., Kang, M. J. \& Han, J. S. Phospholipase D1 increases $\mathrm{BCl}-2$ expression during neuronal differentiation of rat neural stem cells. Mol. Neurobiol. 51, 1089-1102 (2015).
38. Sporik, R., Holgate, S. T., Platts-Mills, T. A. \& Cogswell, J. J. Exposure to housedust mite allergen (Der $p \mathrm{I})$ and the development of asthma in childhood. New Engl. J. Med 323, 502-507 (1990).

39. Sohn, M. H. et al. Calcium-calmodulin mediates house dust mite-induced ERK activation and IL-8 production in human respiratory epithelial cells. Respiration 74, 447-453 (2007)

40. Oh, J. W. et al. Der $f 2$ activates phospholipase $D$ in human T lymphocytes from Dermatophagoides farinae specific allergic individuals: Involvement of protein kinase C-a. Exp. Mol. Med. 36, 486-492 (2004).

41. Hu, T. \& Exton, J. H. 1-Butanol interferes with phospholipase D1 and protein kinase Calpha association and inhibits phospholipase D1 basal activity. Biochem. Biophys. Res. Commun. 327, 1047-1051 (2005).

42. Levine, B. \& Kroemer, G. Autophagy in the pathogenesis of disease. Cell 132 27-42 (2008).

43. Ekokoski, E., Aitio, O., Tornquist, K., Yli-Kauhaluoma, J. \& Tuominen, R. K. HIV-1 Tat-peptide inhibits protein kinase $\mathrm{C}$ and protein kinase $\mathrm{A}$ through substrate competition. Eur. J. Pharm. Sci. 40, 404-411 (2010).

44. Fotin-Mleczek, M. et al. Cationic cell-penetrating peptides interfere with TNF signalling by induction of TNF receptor internalization. J. Cell. Sci. 118, 3339-3351 (2005).

45. Waldeck, W. et al. Transporter molecules influence the gene expression in HeLa cells. Int. J. Med. Sci. 6, 18-27 (2009).

46. Kim, H., Moodley, S. \& Liu, M. TAT cell-penetrating peptide modulates inflammatory response and apoptosis in human lung epithelial cells. Drug Deliv. Transl. Res 5, 275-278 (2015). 